\title{
Study on torsional vibration of RT60 crane transmission system
}

\author{
Nengqi Xiao ${ }^{1,2,}{ }^{*}$, Xiang $\mathrm{Xu}^{1,2}$, and Ruiping Zhou ${ }^{3}$ \\ ${ }^{1}$ Hubei Key Laboratory of Hydroelectric Machinery Design \& Maintenance, China Three Gorges University, Yichang, PR China \\ 2 College of Mechanical and Power Engineering, China Three Gorges University, Yichang, PR China \\ ${ }^{3}$ School of Energy and Power Engineering, Wuhan University of Technology, Wuhan, PR China
}

Received: 15 July 2019 / Accepted: 2 January 2020

\begin{abstract}
In the process of engineering use, the elastic coupling of the RT60 crane transmission system has a large noise and even breaks down sometimes. In this paper, RT60 crane transmission system is the research object. A finite element model and a discrete model for torsional vibration of transmission system are established by finite element method and lumped parameter method. Through the study of the finite element model and the vibration test of transmission system, the correctness of the system model, equivalent parameter, calculation method and MATLAB program are verified. Because of the high efficiency of the torsional vibration discrete system, the discrete model is used in this paper to replace the finite element model. The free vibration and response vibration of the crane transmission system are calculated and analyzed, and the reasons for the existence of the system noise are explained in the starting stage. Through the study of the vibration theory and the matching method of the elastic coupling, the CX-45-VFA-60-11 elastic coupling is proposed to replace the CX-45-VFA-11 elastic coupling. In this paper, the data signal is collected by the hall gear sensor, and the data are analyzed by the self-developed vibration tester. The vibration amplitude of the torsional vibration of the crane transmission system is greatly reduced by testing the transmission system of the replacement of the elastic coupling. This paper provides a theoretical guiding significance for the low noise design of the crane transmission system.
\end{abstract}

Keywords: Crane / torsional vibration / elastic coupling / finite element model / lumped parameter model

\section{Introduction}

With the increasing number of domestic construction industries, including railways, bridges and highways, a crane is widely used as the main equipment in the construction process. A crane is a lifting machine that lifts heavy objects vertically within a certain range. The wheel crane is developed from the crawler crane [1]. It turns the crawler and the walking bracket into the chassis with the tire and overcomes the defects of the crawler's crawler board on the pavement. In the engineering application, the crane has the characteristics of complicated structure, poor working environment, large working load and large vibration [2], which cause the crane transmission system to malfunction. In order to improve the comfort of crane drivers during driving and extend service life of parts of crane transmission system, it is of great significance to study the torsional vibration mechanism and the calculation method of crane transmission system [3,4].

\footnotetext{
* e-mail: xiaonengqi@126.com
}

As a complex vibration system, a crane is composed of several subsystems with inherent vibration characteristics $[5,6]$. The power train is an important source of vibration and the noise of crane, which is composed of power assembly, drive shaft and drive axle assembly [7]. In recent years, it is very urgent to further study the vibration characteristics of the power transmission system with the improvement of the comfort and the vibration of the crane $[8,9]$. The research on torsional vibration characteristics of crane power transmission system is mainly based on traditional theoretical calculation. According to the principle of constant kinetic energy and potential energy, the system is simplified as an equivalent system consisting of inelastic inertia plates and mass-less elastic shafts. According to the equivalent system, the corresponding mechanical model and mathematical model are established to calculate the inherent characteristics of torsional vibration [10,11]. The theoretical analysis method has high accuracy only for the simpler model $[12,13]$. With the development and wide application of computer technology, it has laid a material foundation for the study of torsional vibration. The calculation of the traditional Holzer method 
$[14,15]$, the energy method $[16,17]$ and the amplification factor method [18] can be easily realized by computer. These methods can deal with torsional vibration calculation of complex systems. The continuous development of internal combustion engine to high speed and high power makes the torsional vibration of crane transmission system more intense, and it also causes accidents such as shaft breaking, elastic coupling failure and force transmission bolt failure $[19,20]$. In order to better understand the torsional vibration characteristics of crane transmission system, system matrix method [21] and finite element method are widely used $[22,23]$. Because of the complex structure, multiple excitation sources and operation conditions, the mechanism of vibration is complex and needs further study.

In 1916, the first torsional vibration measurement device was invented by German Geiger. The device had a simple and ingenious measurement principle. It used mechanical structure and separations and torsional vibration of the inertial components. It realized the measurement of the middle and low frequency torsional vibration signals and laid the foundation for the research of torsional vibration measurement technique. With the development of electronic technology and new sensor technology, the torsional vibration measurement technology has made great progress. At present, the torsional vibration measurement technology can be divided into contact type $[24,25]$ and non-contact type, [26,27] according to the relative position relationship between the sensor and the measured axis. The contact torsional vibration measurement technology is a torsional vibration measurement method that the sensor is mounted on the measured axis and rotates along the measured axis $[28,29]$. Generally, it is necessary to use wireless transceiver or slip ring to output electrical signals on the rotating shaft. The non-contact torsional vibration measurement technology is a torsional vibration measurement method that the sensor is not directly connected with the measured shafting [30,31]. The instantaneous change speed is measured directly through the speed sensor, and the instantaneous change speed signal is converted to the electrical signal, and the torsional vibration signal is extracted by electronic technology or data processing.

In this paper, a finite element model and a discrete model of the torsional vibration of a transmission system are established by taking the crane transmission system as the research object. The finite element method and the system matrix method are used to calculate and analyze the free vibration of the transmission system, and the correctness of the transmission system model and the equivalent parameters are verified. The system matrix method and the flexible coupling vibration theory are used to calculate and analyze the forced vibration of the crane transmission system. In order to reduce the vibration of the crane transmission system, the most reasonable elastic coupling is matched for the transmission system. By testing the torsional vibration of the crane, the correctness of the elastic coupling technique and the theoretical calculation method of torsional vibration are verified.

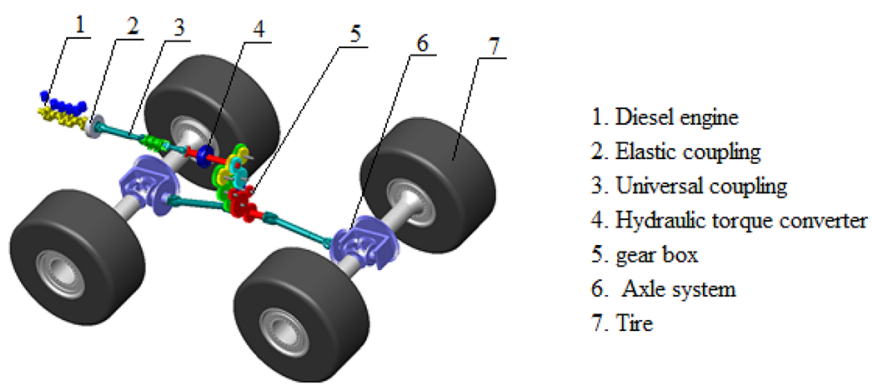

Figure 1. Equivalent system diagram of crane transmission system.

\section{Modeling of crane transmission system}

Because the crane is widely used in road and bridge projects, housing construction projects and large water conservancy and hydropower construction projects, its working environment and operation condition are relatively poor, so the crane drive system failure frequency is higher. Through the analysis and classification of the fault characteristics of a series of crane transmission systems, the failure of the elastic coupling component of crane is one of the important faults. The main reason for the failure of elastic couplings is caused by torsional vibration of crane shafting. In this paper, the torsional vibration characteristics of crane transmission system and the influence rule of elastic coupling on torsional vibration are analyzed and studied with RT60 crane as the research object.

The transmission system of RT60 heavy cranes is composed of diesel engine, high elastic coupling, universal coupling, torque converter, gearbox, differential, main reducer, front and rear axle, tire and so on, as shown in Figure 1. The heavy crane has the characteristics of complex operating conditions and heavy transmission load, which leads to high damage probability of elastic coupling and other parts. In order to optimize the vibration characteristics of the crane transmission system and increase the life of the elastic coupling, this paper studies the matching of the elastic coupling based on the vibration of the transmission system.

The high elastic coupling of the transmission shaft of the construction machinery is subjected to high speed, high torque and strong impact, and at the same time it also suffers from high temperature, fuel and lubricating oil pollution. In addition, with the further improvement of the performance requirements of construction machinery, the requirements for the vibration of transmission shaft of construction machinery are getting higher and higher. Therefore, with the development of construction machinery technology, it is more and more important to select the high elastic coupling of transmission shaft, correctly. The principle of high elastic vibration reduction can be explained by the simplest double quality system. It has a certain guiding function in practical application. In this paper, the model and vibration theory of elastic coupling are studied firstly. The elastic coupling is converted into a double mass system, as shown in Figure 2. 

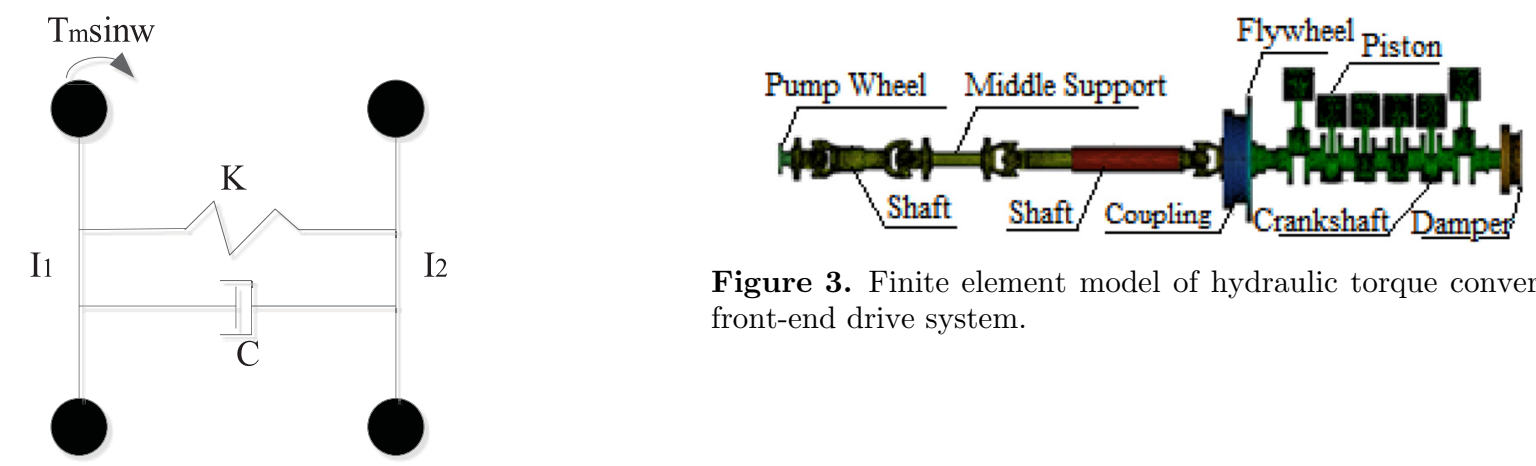

Figure 3. Finite element model of hydraulic torque converter front-end drive system.

Figure 2. Two-quality system of high elastic coupling.

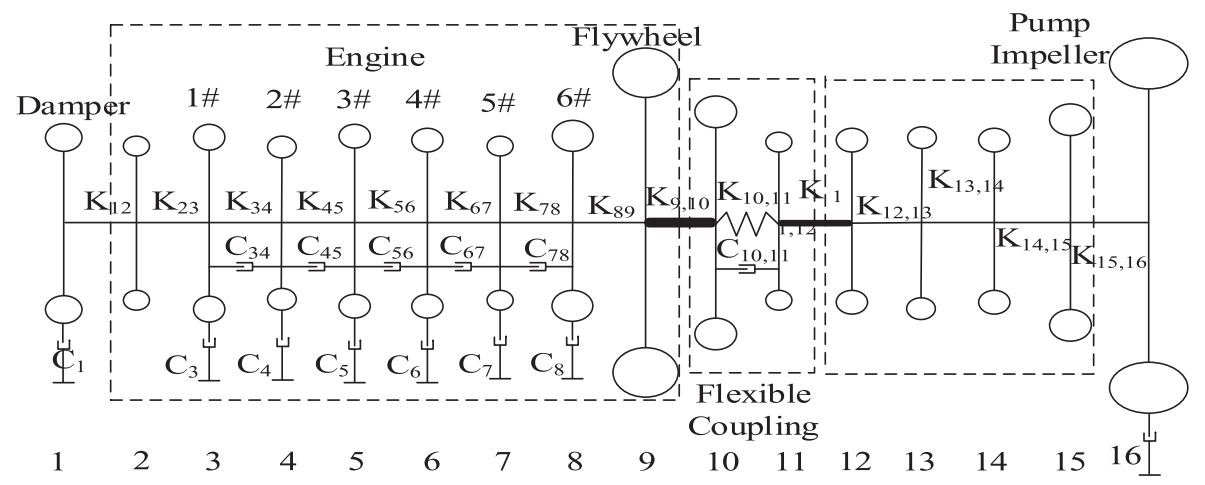

Figure 4. Equivalent system diagram of crane transmission system.

According to the theory of torsional vibration, the vibration differential equation of elastic coupling can be established as follows.

$$
\begin{gathered}
I_{1} \ddot{\theta}_{1}+C\left(\dot{\theta}_{1}-\dot{\theta}_{2}\right)+K\left(\theta_{1}-\theta_{2}\right)=T_{m} \sin \omega \\
I_{2} \ddot{\theta}_{2}+C\left(\dot{\theta}_{2}-\dot{\theta}_{1}\right)+K\left(\theta_{2}-\theta_{1}\right)=0
\end{gathered}
$$

where $I_{1}$ is the active end inertia (the excitation end). $I_{2}$ is the inertia of driven end. $K$ is the coupling stiffness. $C$ is the coupling damping coefficient. $T_{\mathrm{m}} \sin \omega$ is the excitation torque.

According to the principle of mechanical vibration, the vibration torque transmitted by couplings is

$$
T(t)=C\left(\dot{\theta}_{2}-\dot{\theta}_{1}\right)+K\left(\theta_{2}-\theta_{1}\right)
$$

By solving differential equations (1)-(3), the particular solution (steady-state solution) is obtained, and the amplitude of $T$ is

$$
T=\frac{I_{2}}{\left(I_{1}+I_{2}\right)} T_{m} \sqrt{\frac{1+\left(\frac{C \omega}{K}\right)^{2}}{\left(1-\frac{\omega^{2}}{\omega_{n}^{2}}\right)^{2}+\left(\frac{C \omega}{K}\right)^{2}}}
$$

where $\omega_{n}^{2}=K \frac{I_{1}+I_{2}}{I_{1} I_{2}}$
In the calculation and analysis of the torsional vibration of the crane shafting, it can be divided into two independent torsional vibration systems. The system includes diesel engine, torque converter, pump wheel system and turbine tire system. This paper focuses on diesel engine, hydraulic torque converter and pump wheel system. The finite element model and discrete model of the transmission system are established by finite element method and lumped parameter method, respectively. The finite element model of the transmission system is built with finite element software, as shown in Figure 3.

The torsional vibration model of a diesel engine to a hydraulic torque converter is established by using lumped parameter method, as shown in Figure 4. The torsional vibration equivalent parameters of the system are given in Table 1.

\section{Vibration calculation and analysis of crane transmission system}

In order to get the torsional vibration model of transmission system in Figure 4, the model of the components of the transmission system is established. The torsional vibration model of the transmission system is composed of 16 lumped inertia units and 15 massless spring elements. The torsional vibration model shown in Figure 4 can be divided into several direct chain vibration models, as shown in Figure 5. 
Table 1. Torsional vibration model of transmission system.

\begin{tabular}{|c|c|c|c|c|c|c|c|c|c|c|c|}
\hline No. & $\begin{array}{l}\text { Inertia } \\
\left(\mathrm{kgm}^{2}\right)\end{array}$ & $\begin{array}{l}\text { Stiffness } \\
(\mathrm{MNm} / \mathrm{rad})\end{array}$ & $\begin{array}{l}\text { Out- } \\
\text { diameter } \\
(\mathrm{mm})\end{array}$ & $\begin{array}{l}\text { In- } \\
\text { diameter } \\
(\mathrm{mm})\end{array}$ & Identified & No. & $\begin{array}{l}\text { Inertia } \\
\left(\mathrm{kgm}^{2}\right)\end{array}$ & $\begin{array}{l}\text { Stiffness } \\
(\mathrm{MNm} / \mathrm{rad})\end{array}$ & $\begin{array}{l}\text { Out- } \\
\text { diameter } \\
(\mathrm{mm})\end{array}$ & $\begin{array}{l}\text { In- } \\
\text { diameter } \\
(\mathrm{mm})\end{array}$ & Identified \\
\hline 2 & 0.0200 & 2.0400 & 70.0 & 0.0 & Sprocket & 10 & 0.4570 & 0.0070 & - & 0.0 & Elastic coupling \\
\hline 3 & 0.0410 & 1.3300 & 69.0 & 0.0 & Cylinder 1\# & 11 & 0.1530 & - & 0 & - & Elastic coupling \\
\hline 4 & 0.0280 & 1.3300 & 69.0 & 0.0 & Cylinder 2\# & 12 & 0.0472 & 1.500 & 90.0 & 85.0 & Shaft \\
\hline 7 & 0.0280 & 1.3300 & 69.0 & 0.0 & Cylinder 5\# & 15 & 0.0500 & 3.7000 & 65.0 & 51.0 & Shaft \\
\hline 8 & 0.0450 & 1.2100 & 69.0 & 0.0 & Cylinder $6 \#$ & 16 & 0.8640 & - & - & - & Pump wheel \\
\hline
\end{tabular}

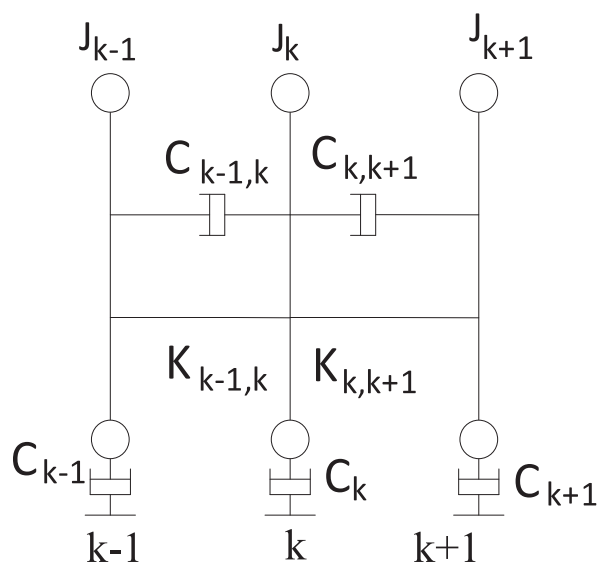

Figure 5. Torsional vibration model of straight chain.

According to the model and mechanical vibration theory, the torsional vibration differential equation of the $k$ th mass point can be established.

$$
\begin{aligned}
J_{k} \ddot{\phi}_{k} & +C_{k} \dot{\phi}_{k}+C_{k-1, k}\left(\dot{\phi}_{k}-\dot{\phi}_{k-1}\right)+C_{k, k+1}\left(\dot{\phi}_{k}-\dot{\phi}_{k+1}\right) \\
& +K_{k-1, k}\left(\phi_{k}-\phi_{k-1}\right)+K_{k, k+1}\left(\phi_{k}-\phi_{k+1}\right)=T_{k}(t)
\end{aligned}
$$

Equation (4) can be converted to:

$$
\begin{aligned}
J_{k} \ddot{\phi}_{k} & +\left(C_{k-1, k}+C_{k, k+1}\right) \dot{\phi}_{k}-C_{k-1, k} \dot{\phi}_{k-1}-C_{k, k+1} \dot{\phi}_{k+1} \\
& +\left(K_{k-1, k}+K_{k, k+1}\right) \phi_{k}-K_{k-1, k} \phi_{k-1}-K_{k, k+1} \phi_{k+1} \\
& +C_{k} \dot{\phi}_{k}=T_{k}(t)
\end{aligned}
$$

where $T_{k}(t)$ is the excitation moment, in Nm. $J_{k}$ is the $k$ th mass point's inertia, in $\mathrm{kg} \cdot \mathrm{m}^{2} . K_{k, k+1}$ is stiffness between the $k$ th mass point and the $K+1$ mass point, in Nm $/ \mathrm{rad} . C_{k}$ and $C_{k, k+1}$ are external damping coefficients and internal damping coefficients, in Nms $/ \mathrm{rad} . \phi_{k}, \dot{\phi}_{k}$ and $\phi_{k}$ represent angular displacement, angular velocity and angular acceleration.

In the torsional vibration model of the general complex system, there are not only the conventional direct chain torsional vibration sub-models, but also the torsional vibration sub-models with branches, as shown in Figure 6.

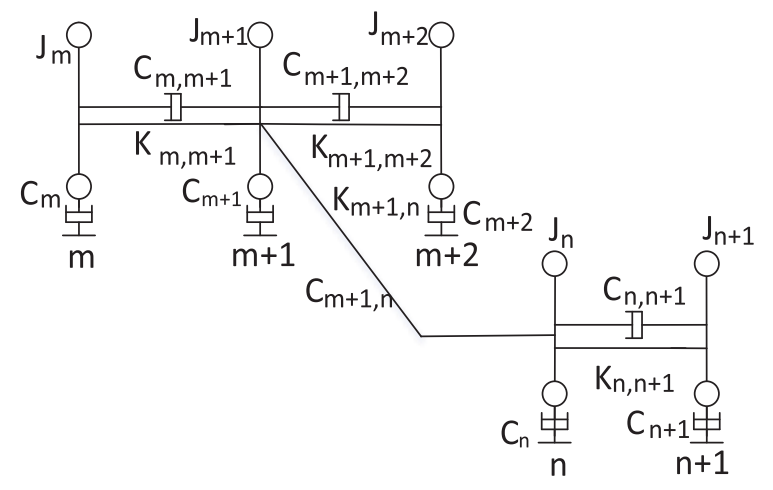

Figure 6. Torsional vibration model of branch chain.

Through the analysis of the model shown in Figure 6 , the torsional vibration differential equation of the $m+1$ mass point can be obtained by the same reason.

$$
\begin{aligned}
J_{m+1} & \ddot{\phi}_{m+1}+C_{m, m+1}\left(\dot{\phi}_{m+1}-\dot{\phi}_{m}\right) \\
& +C_{m+1, m+2}\left(\dot{\phi}_{m+1}-\dot{\phi}_{m+2}\right)+K_{m, m+1}\left(\phi_{m+1}-\phi_{m}\right) \\
& +K_{m+1, m+2}\left(\phi_{m+1}-\phi_{m+2}\right)+C_{m+1} \dot{\phi}_{m+1} \\
& +C_{m+1, n}\left(\dot{\phi}_{m+1}-\dot{\phi}_{n}\right)+K_{m+1, n}\left(\phi_{m+1}-\phi_{n}\right) \\
= & T_{m+1}(t)
\end{aligned}
$$

Equation (6) can be converted to:

$$
\begin{aligned}
& J_{m+1} \ddot{\phi}_{m+1}+\left(C_{m, m+1}+C_{m+1, m+2}+C_{m+1, n}\right) \dot{\phi}_{m+1} \\
& \quad-C_{m, m+1} \dot{\phi}_{m}-C_{m+1, n} \dot{\phi}_{n}-C_{m+1, m+2} \dot{\phi}_{m+2} \\
& \quad+\left(K_{m, m+1}+K_{m+1, m+2}+K_{m+1, n}\right) \phi_{m+1}-K_{m, m+1} \phi_{m} \\
& \quad-K_{m+1, m+2} \phi_{m+2}-K_{m+1, n} \phi_{n}+C_{m+1} \dot{\phi}_{m+1}=T_{m+1}(t)
\end{aligned}
$$

where the meaning of each parameter in equations (4) and (5) is the same as described above.

To sum up, the torsional vibration equation of the torsional vibration model of the transmission system shown 


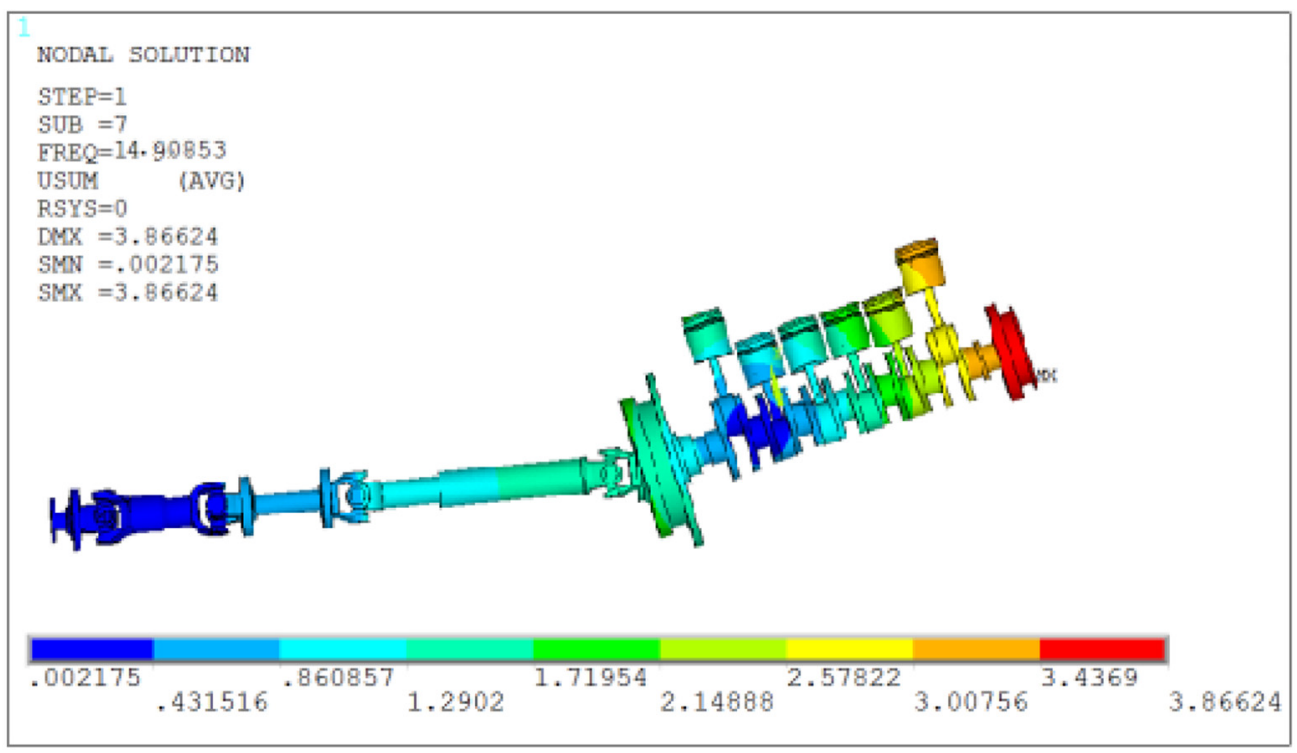

Figure 7. First order mode of the transmission system.

Table 2. Free vibration natural frequency.

\begin{tabular}{lllll}
\hline $\mathrm{Wn} /$ Harmonic & 1 & 2 & 3 & 4 \\
\hline $\mathrm{r} / \mathrm{min}$ & 935.48 & 11358.29 & 14927.89 & 32080.21 \\
$\mathrm{~Hz}$ & 15.60 & 189.39 & 248.91 & 534.90 \\
\hline
\end{tabular}

in Figure 4 can be obtained.

$$
[J]\{\phi\}+[C]\{\dot{\phi}\}+[K]\{\phi\}=\{T(t)\}
$$

where the damping matrix $[C]$ can be divided into $[C]=\left[C^{\prime}\right]+\left[C^{\prime}\right] \cdot[C]$ is the external damping matrix, which is consistent with the inertia matrix. $\left[C^{\prime}\right]$ is the internal damping matrix, which is consistent with the stiffness matrix. $T(t)$ is the vector of the excitation torque. $[J]$ is the inertia matrix. $[K]$ is the stiffness matrix.

$$
\begin{aligned}
& {[J]=\left[\begin{array}{cccc}
J_{1} & 0 & \ldots & 0 \\
0 & J_{2} & \ldots & \ldots \\
\ldots & \ldots & . & 0 \\
0 & \ldots & 0 & J_{n}
\end{array}\right]} \\
& {[K]=\left[\begin{array}{ccccc}
K_{1,2} & -K_{1,2} & & & \\
-K_{1,2} & K_{1,2}+K_{2,3} & & & \\
\cdots & \cdots & \cdots & \cdots & \cdots \\
& & & K_{n-2, n-1}+K_{n-1, n} & -K_{n-1, n} \\
& & & -K_{n-1, n} & K_{n-1, n}
\end{array}\right]}
\end{aligned}
$$

According to equation (8) and the equivalent parameters of transmission system, the system matrix method and MATLAB software can be used to calculate the natural frequency value of the system, as shown in Table 2.

The calculation method of the resonance speed $n_{c}$ is as follows

$$
n_{c}=\frac{N_{i}}{v}
$$

where $N_{i}$ is the natural frequency of the $i$ th order, Hz. $V$ is a harmonic time. $n_{c}$ is the resonant speed, Hz.

According to the above calculation method, the resonant speed of the system can be obtained at various harmonic times. In the operating speed range of diesel engine $(750 \mathrm{r} / \mathrm{min}-2200 \mathrm{r} / \mathrm{min})$, the first three order natural frequencies of the system may be consistent with the diesel excitation frequency, which may lead to system resonance. But the main harmonic rotational speed of the diesel engine is about $311.8 \mathrm{r} / \mathrm{min}$, which is outside the normal working speed of the diesel engine, and falls on the starting stage of the diesel engine. The crane transmission system will have a large vibration noise in the start-up moment. The vibration noise may be caused by the resonance speed falling in the start-up phase.

In order to verify the correctness of discrete model, equivalent parameter and natural frequency value, modal analysis of crane transmission system in Figure 3 is carried out by ANSYS-finite element analysis software. The natural frequency value of torsional vibration is extracted by the vibration characteristics. The torsional vibration modal analysis results of cx-45-vfa- 11 elastic coupling drive system can be obtained by calculation. Due to space limitation, this paper only gives the finite element calculation results of the first two order natural frequency values of the transmission system, as shown in Figures 7 and 8 . 


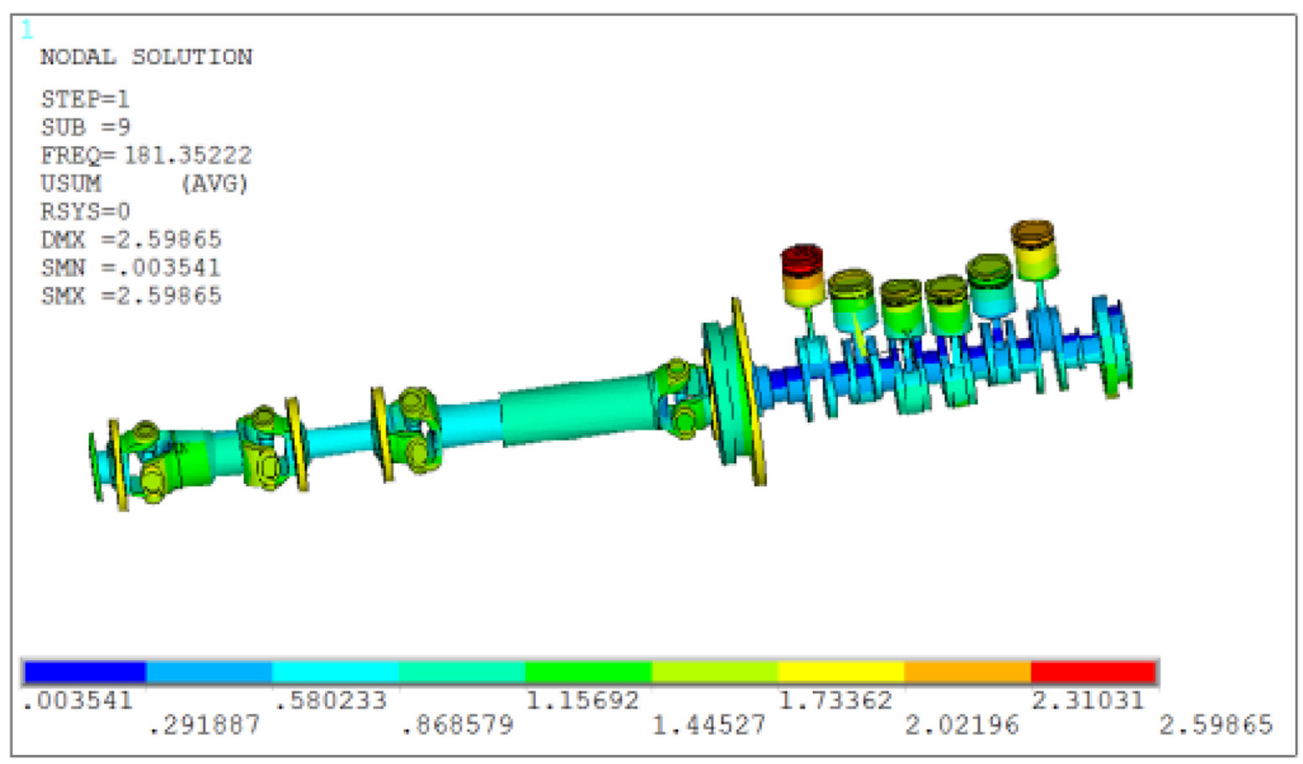

Figure 8. Second order mode of the transmission system.

Table 3. Comparison of free vibration results between finite element model and discrete model.

\begin{tabular}{llll}
\hline Wn/ Harmonic & 1 & 2 & 3 \\
\hline Finite element model $(\mathrm{Hz})$ & 14.91 & 181.35 & 237.71 \\
Discrete model $(\mathrm{Hz})$ & 15.60 & 189.39 & 248.91 \\
Error value & $4.63 \%$ & $4.43 \%$ & $4.71 \%$ \\
\hline
\end{tabular}

Through the finite analysis and calculation of the established transmission system model, the first three natural frequencies of the system are $14.91 \mathrm{~Hz}, 181.35 \mathrm{~Hz}$ and $237.71 \mathrm{~Hz}$, respectively. As shown in Table 2, the natural frequencies of the torsional vibration of the discrete model of the transmission system calculated by the system matrix method are given. The first three natural frequencies of the system are $15.60 \mathrm{~Hz}, 189.39 \mathrm{~Hz}$ and $248.91 \mathrm{~Hz}$, respectively. After comparing the results of the finite element analysis with the results of the system matrix method, the error values are $4.63 \%, 4.43 \%$ and $4.71 \%$, respectively. The error value is within the allowable range, and the correctness of the transmission system discrete model, equivalent parameter and calculation method is verified, as shown in Table 3.

For the analysis of elastic coupling (CX-45-VFA-11) torsional vibration characteristics and improving the computational efficiency of the transmission system, forced vibration analysis is carried out on the discrete model of torsional vibration of transmission system. In the range of $200 \mathrm{r} / \mathrm{min}-2420 \mathrm{r} / \mathrm{min}$, the speed range was divided into 121 points. The torsional vibration characteristics of crane transmission system at 121 speed points are solved by system matrix method, and the torsional

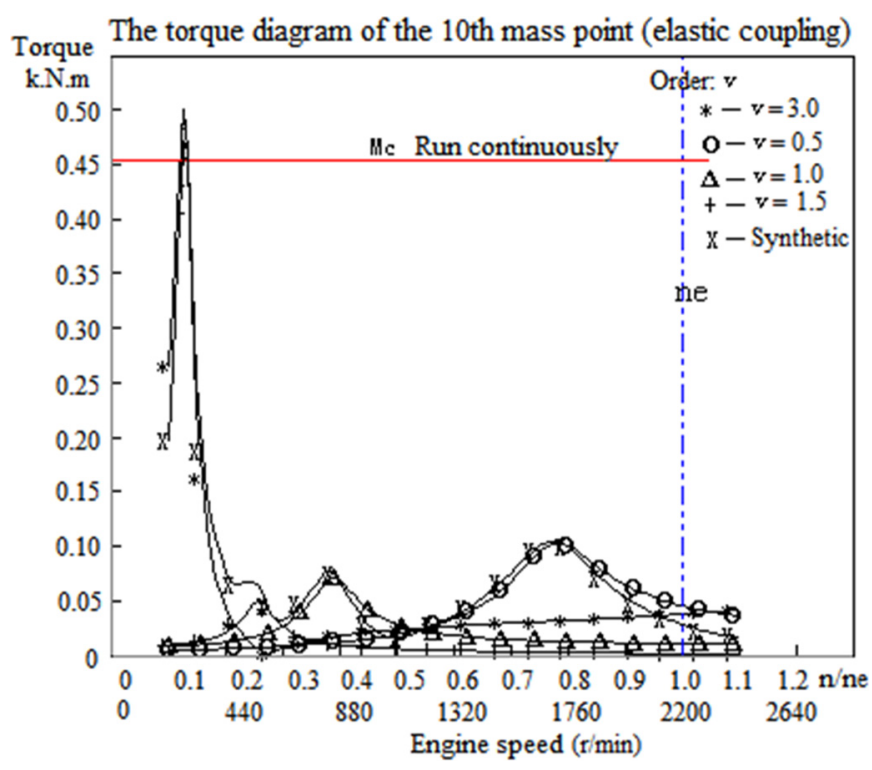

Figure 9. Vibration torque diagram of elastic coupling.

vibration curve of crane transmission system is drawn. The vibration torque curve of the elastic coupling of crane transmission system can be obtained by calculation, as shown in Figure 9.

According to the results of the vibration calculation shown in Figure 9:

- When the crane transmission system operates at the range of $750 \mathrm{r} / \mathrm{min}-2200 \mathrm{r} / \mathrm{min}$, the maximum torsional vibration torque of the elastic coupling is $0.11 \mathrm{kNm}$. Because the maximum vibration torque value is less than the allowable value, the crane transmission system can work normally within this speed range. 


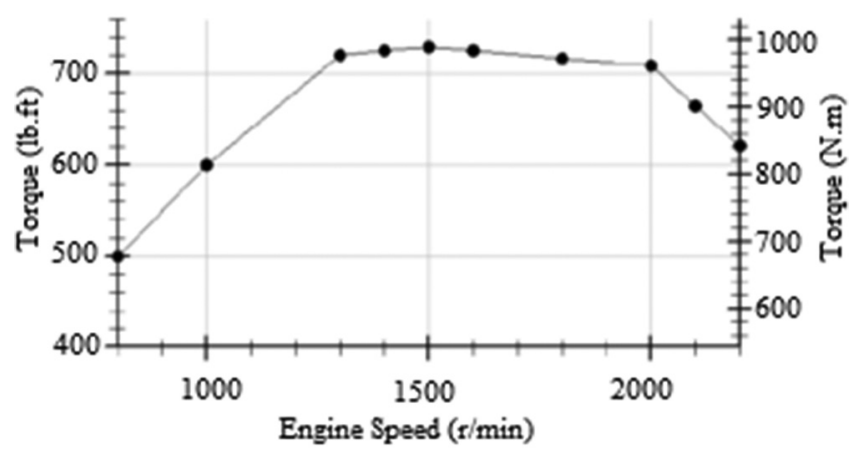

Figure 10. Torque curve of diesel engine.

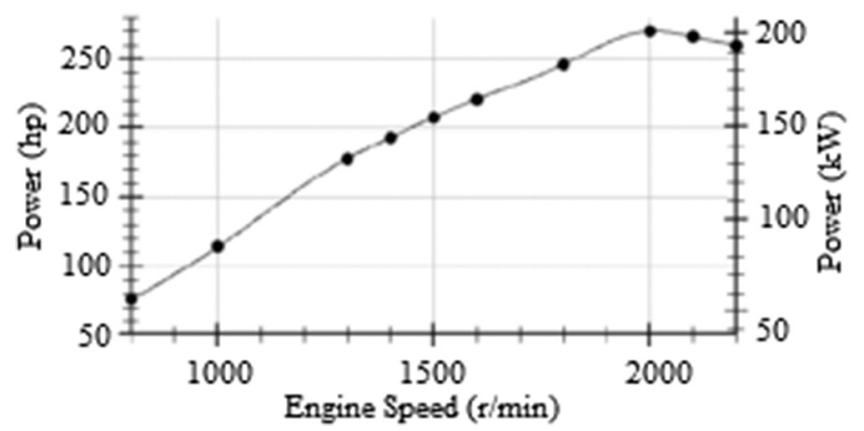

Figure 11. Power curve of diesel engine.

Table 4. Resonance speed changing with stiffness.

\begin{tabular}{llllll}
\hline No. & $\begin{array}{l}\text { Elastic coupling stiffness } \\
(\mathrm{N} . \mathrm{m} / \mathrm{rad})\end{array}$ & $\begin{array}{l}\text { 3 harmonic resonance } \\
\text { speed in first order } \\
(\mathrm{r} / \mathrm{min})\end{array}$ & No. & $\begin{array}{l}\text { Elastic coupling } \\
\text { stiffness (N.m/rad) }\end{array}$ & $\begin{array}{l}3 \text { harmonic resonance } \\
\text { speed in first order } \\
(\mathrm{r} / \mathrm{min})\end{array}$ \\
\hline 1 & 3000 & 209.03 & 10 & 21000 & 547.33 \\
2 & 5000 & 269.54 & 11 & 23000 & 572.15 \\
3 & 7000 & 318.56 & 12 & 25000 & 595.83 \\
4 & 9000 & 360.8 & 13 & 29000 & 640.26 \\
5 & 11000 & 398.33 & 14 & 33000 & 681.42 \\
6 & 13000 & 432.63 & 15 & 35000 & 700.97 \\
7 & 15000 & 464.18 & 16 & 39000 & 738.25 \\
8 & 17000 & 493.59 & 17 & 40000 & 747.23 \\
9 & 19000 & 521.22 & 18 & 41000 & 756.08 \\
\hline
\end{tabular}

- When the diesel engine speed is less than $750 \mathrm{r} / \mathrm{min}$, the crane transmission system is in start-up phase. When the diesel engine speed is $310 \mathrm{r} / \mathrm{min}$, the torsional vibration torque value of the elastic coupling is $0.50 \mathrm{kNm}$. Since the vibration torque value of the system exceeds the allowable value, the crane transmission system will have abnormal noise and even the elastic coupling will be broken during the starting process.

In the engineering practice, the elastic coupling (CX45-VFA-11) of the RT60 crane transmission system was found to have an abnormal ring or fracture during the startup process. In order to solve the failure of the elastic coupling of the transmission system, the elastic coupling of the transmission system is calculated and studied according to the elastic coupling theory and the system discrete mathematical model.

The original motive of the RT60 crane transmission system is the QSB6.7 model diesel engine of Cummins company. The torque curve and power curve of the diesel engine are shown in Figures 10 and 11.

As can be seen from Figures 10 and 11, when the diesel engine speed is $2000 \mathrm{r} / \mathrm{min}$, the maximum power is $201 \mathrm{~kW}$. When the speed is $1500 \mathrm{r} / \mathrm{min}$, the maximum torque is $990 \mathrm{Nm}$. Therefore, considering the temperature influence and working conditions of the high elastic couplings, the rated torque of the selected high-elastic couplings should be no less than $1800 \mathrm{Nm}$.
In order to avoid abnormal noise or elastic coupling damage in crane transmission system, the dynamic stiffness of the selected coupling should minimize the strong torsional resonance in the working speed $\left(750 \mathrm{r} / \mathrm{min}^{-}\right.$ $2100 \mathrm{r} / \mathrm{min}$ ) range of the crane. According to the established torsional vibration model and the equivalent parameters of the system shown in Table 1, the resonant speed of the crane transmission system is calculated at 3 harmonics when the stiffness value of the elastic coupling is within 3000-41 000, as shown in Table 4.

According to the calculation results of Table 4 and the working speed $(750 \mathrm{r} / \mathrm{min}-2100 \mathrm{r} / \mathrm{min})$ of the crane transmission system, the dynamic stiffness of the selected high elastic coupling should be at 3000-41 $000 \mathrm{Nm} / \mathrm{rad}$. By consulting the manufacturer's flexible coupling selection manual, the CX-45-VFA-60-11 type elastic coupling replaces CX-45-VFA-11 type elastic coupling in the RT60 crane transmission system.

\section{Vibration test and analysis of the crane transmission system}

\subsection{Test principle and measurement point arrangement}

This test only has two measuring points on the transmission shaft system, as shown in Figure 12. One of the 


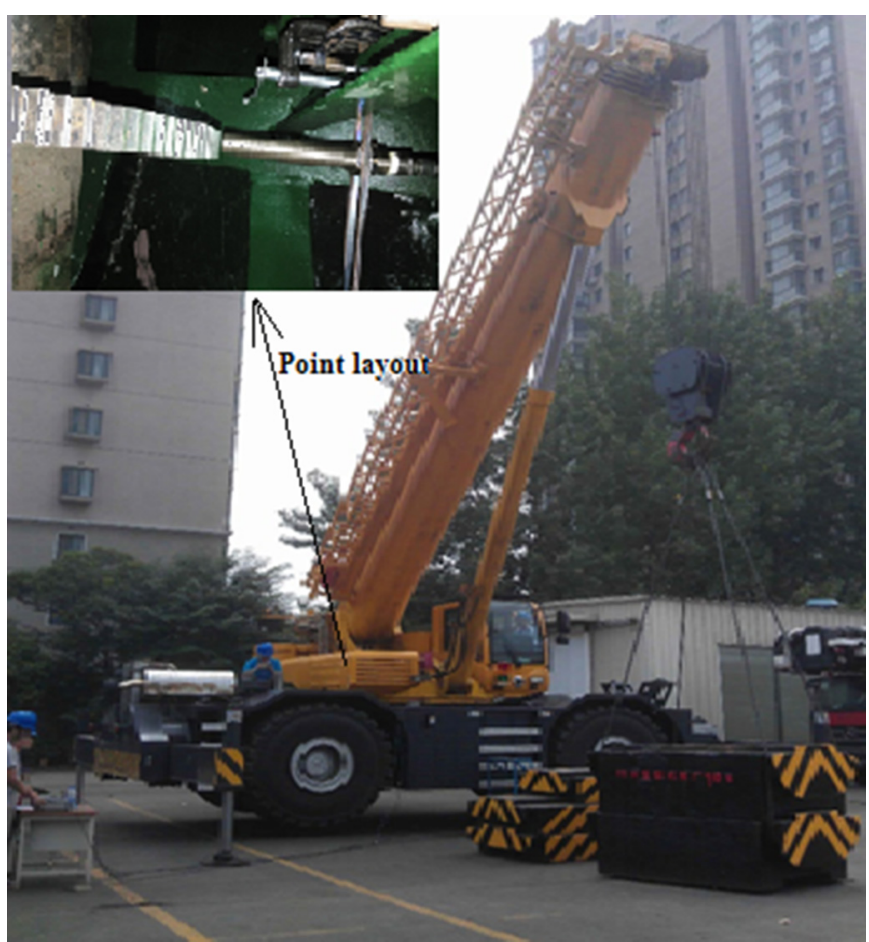

Figure 12. Layout of torsional vibration measurement point.

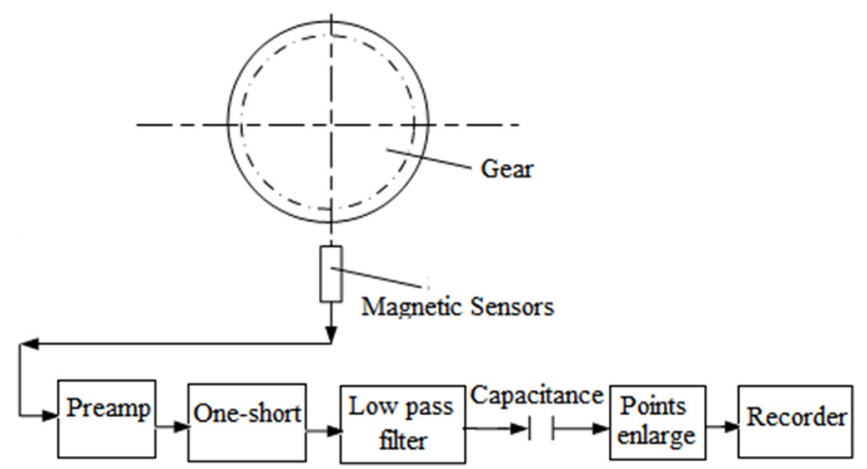

Figure 13. Test principles of non-contact measuring method.

measuring points is arranged at the flywheel, and the other one is arranged in the elastic coupling from the moving end flange. In the course of testing, two measuring points are collected simultaneously with the self-developed YDZT2013 model torsional vibration test instrument. By using the Hall Gear sensor to obtain the signal, the sensor and the shafting vibration tester are connected by the shielding cable to realize the data collection and storage. The measured data are analyzed by the computer special analysis software, and the frequency spectrum data and frequency speed curve of each test condition are obtained.

The sensor used in the test system is an eddy current sensor. The non-contact electrical measuring method is adopted to improve the shafting torsional vibration testing, as shown in Figure 13. When using the sensors of $\mathrm{N}$ grating pulses or gear pulses per revolution, the $\mathrm{N}$ pulse signals

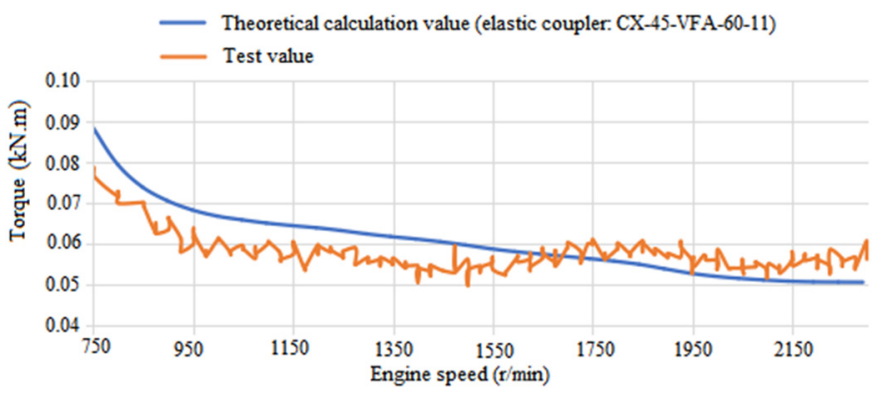

Figure 14. Comparison of theoretical and measured values of vibration torque of elastic couplings (CX-45-VFA-60-11).

with different output periods per revolution will be generated due to the fluctuation of instantaneous speed. Since the time of each pulse signal is $t_{i}$, the average speed of $\bar{\omega}$ and instantaneous speed $\omega_{\mathrm{i}}$ can be obtained.

$$
\begin{gathered}
\bar{\omega}=2 \pi / \sum_{i=1}^{N} t_{i}(\mathrm{rad} / \mathrm{s}) \\
\omega_{i}=(2 \pi / \mathrm{N}) / t_{i}(\mathrm{rad} / \mathrm{s})
\end{gathered}
$$

\subsection{Test and analysis}

According to the above survey point layout and testing instrument, sensors and testing instruments are installed on the RT60 crane, as shown in Figure 14. The data acquisition of the transmission system is carried out under the crane lifting condition. According to the above test principle and vibration measuring point, the torsional vibration test is carried out for the transmission system of type CX-45-VFA-60-11 elastic coupling. Due to the short start-up time of the crane, this instrument cannot measure the torsional vibration of the transmission system within the range of $0-750 \mathrm{r} / \mathrm{min}$. Therefore, the torsional vibration characteristics of the drive system are measured in the working speed range. The results of the test are shown in Figure 14. When testing the speed range of normal operation of cranes, vibration data acquisition started at $750 \mathrm{r} / \mathrm{min}$ of diesel engine, and the speed interval is increased to $50 \mathrm{r} / \mathrm{min}$.

- After replacing the elastic coupling, the crane transmission system runs smoothly at start-up, and there is no abnormal sound.

- By comparing the calculated results with the measured values, the error between the theoretical value and the measured value is about $\pm 10 \%$. The torsional vibration model, equivalent parameter and calculation method of crane transmission system are verified.

- The theoretical value of the elastic coupling torque shown in Figure 9 is compared with the elastic coupling value shown in Figure 14. In the range of $750 \mathrm{r} / \mathrm{min}-2200 \mathrm{r} /$ min speed, the maximum torque of the elastic coupling (CX-45-VFA-11) is $0.110 \mathrm{kN} . \mathrm{m}$, but the maximum torque of the elastic coupling (CX-45-VFA-60-11) of the 
transmission system is $0.088 \mathrm{kN} . \mathrm{m}$. Therefore, the vibration torque value of the elastic coupling of the transmission system is reduced by $20 \%$ after the replacement of the elastic coupling.

\section{Conclusion}

- In this paper, the finite element method and the lumped parameter method are used to construct the finite element model and the discrete model for calculation of the torsional vibration of the crane transmission system. The correctness of the discrete model, the equivalent parameter, the calculation method and the MATLAB program are verified by the results of the finite element calculation and the test results of the vibration.

- The free vibration and forced vibration of the RT60 type crane transmission system of the CX-45-VFA-11 type elastic coupling are calculated and analyzed. It is found that there are obvious resonance points and large amplitude in the starting phase of the crane drive system. The torsional vibration characteristics of crane transmission system are analyzed.

- The excessive torsional vibration will result in the abnormal sound of the elastic coupling and even the damage of the crane transmission system. Through the study of the theory and matching method of elastic coupling, CX-45-VFA-60-11 type elastic coupling is proposed to replace CX-45-VFA-11 type elastic coupling. After the replacement of the elastic coupling, the vibration amplitude of the RT60 crane transmission system is reduced by $20 \%$.

- The torsional vibration signal of crane transmission system is obtained through the hall gear sensor, and the data acquisition and analysis are carried out by the selfdeveloped torsional vibration instrument. The test method is helpful to understand the torsional vibration characteristics of crane transmission system. This paper provides guidance for the low noise design of a crane transmission system.

The authors would also like to thank the editors and anonymous reviewers for their insightful comments that helped improve this paper. The author(s) disclosed receipt of the following financial support for the research, authorship, and/or publication of this article: the authors acknowledge the support of the National Natural Science Foundation of China (No. 51479154) and Tsinghua university open fund (grant number KF16222).

\section{Conflict of interest}

The author(s) declared no potential conflicts of interest with respect to the research, authorship, and/or publication of this article.

\section{References}

[1] W. He, S. Zhang, S.S. Ge, Adaptive control of a flexible crane system with the boundary output constraint, IEEE Trans. Ind. Electron. 61, 4126-4133 (2014)
[2] P. Romanowicz, Numerical assessment of fatigue load capacity of cylindrical crane wheel using multiaxial highcycle fatigue criteria. Arch. Appl. Mech. 87, 1-20 (2017)

[3] A. Zankl, E.L. Duncan, et al. Vibration test and analysis system for construction machinery based on labwindows/ CVI, Metrol. Meas. Tech. 90, 494-501 (2008)

[4] L.F. Stikeleather, Evaluating the vibration and shock isolation qualities of operator seats for construction machinery, Synth. Commun. 39, 1929-1935 (1973)

[5] J.E. Johnson, D.E. Wasserman, Ergonomics and vibration in powered hand tools used in meat processing, J. Low Freq. Noise Vib. Active Control 19, 1-15 (2000)

[6] J. Wu, Q. Wu, L. Ma, et al. Parameter vibration and dynamic stability of the printing paper web with variable speed, J. Low Fr eq. Noise Vib. Active Control 29, 281-291 (2010)

[7] S. Kotake, K. Yagi, T. Takigami, Application of sampleddata control by using vibration manipulation function to suppress residual vibration of travelling crane, Mech. Eng. J. 2, 15-00033-15-00033 (2015)

[8] A. Arena, W. Lacarbonara, A. Casalotti, et al., Payload oscillations control in harbor cranes via semi-active vibration absorbers: modeling, simulations and experimental results, Procedia Eng. 199, 501-509 (2017)

[9] D. Kang, W.S. Lee, et al., Characteristics of construction machinery noise and vibration, Trans. Korean Soc. Noise Vib. Eng. 15, 645-651 (2005)

[10] C.W. Lim, L. Cheng, Y. Jinlin, Free torsional vibration of nanotubes based on nonlocal stress theory, J. Sound Vib. 331, 2798-2808 (2012)

[11] A.M. Najafov, A.H. Sofiyev, N. Kuruoglu, Torsional vibration and stability of functionally graded orthotropic cylindrical shells on elastic foundations, Meccanica 48, 829-840 (2013)

[12] A. Alexander, A. Vacca, D. Cristofori, Active vibration damping in hydraulic construction machinery, Procedia Eng. 176, 514-528 (2017)

[13] J. Chen, R.B. Randall, B. Peeters, Advanced diagnostic system for piston slap faults in IC engines, based on the nonstationary characteristics of the vibration signals, Mech. Syst. Signal Process. 75, 434-454 (2016)

[14] C. Peeters, P. Guillaume, J. Helsen, A comparison of cepstral editing methods as signal pre-processing techniques for vibration-based bearing fault detection., Mech. Syst. Signal Process. 91, 354-381 (2017)

[15] D. Remond, Practical performances of high-speed measurement of gear transmission error or torsional vibrations with optical encoders, Meas. Sci. Technol. 9, 347-353 (1998)

[16] T.W. Spaetgens, B.C. Vancouver, Holzer method for forceddamped torsional vibrations, J. Appl. Mech. Trans. ASME 17, 59-63 (1950)

[17] H.E. Fettis, Vibration modes of a two-beam system by the Holzer method, J. Aerosp. Sci. 29, 15-20 (2014)

[18] B.A.J. Mustafa, A. Roszaidi, An energy method for free vibration analysis of stiffened circular cylindrical shells, Comput. Struct. 32, 355-363 (1989)

[19] T. Hermann, M. Witalis, Assessment of the effectiveness of anti-vibration gloves. A comparison of the conventional and energy method. analysis and interpretation of results-Part Two, Vib. Phys. Syst. 28, 1-9 (2017)

[20] Z.-g. Song, Y. Zhang, Analysis of the dynamic amplification factor of latetral structural vibration induced by crowdbridge interaction, J. Vib. Shock 34, 19-23 (2015) 
[21] R. Feldhaus, H. Bach, System considerations concerning alternative torsion vibration dampers in automobile drive trains, Atz Worldwide 104, 12-16 (2002)

[22] W. Homik, Diagnostics, maintenance and regeneration of torsional vibration dampers for crankshafts of ship diesel engines, Pol. Marit. Res. 17, 62-68 (2010)

[23] N. Xiao, R. Zhou, X. Xu, Vibration of diesel-electric hybrid propulsion system with nonlinear component, J. Vib. Control 24, 5353-5365 (2018)

[24] J.-J. Wu, Finite element analysis and vibration testing of a three-dimensional crane structure, Measurement 39, 740749 (2006)

[25] A. Lazarus, B. Prabel, D. Combescure, A 3D finite element model for the vibration analysis of asymmetric rotating machines, J. Sound Vib. 329, 3780-3797 (2017)
[26] S.H. Kia, H. Hena, A comparative study of acoustic vibration and stator current signatures for gear tooth fault diagnosis, IEEE 2012, pp. 1514-1519

[27] J. Rajnauth, Reduce torsional vibration and improve drilling operations, Int. J. Appl. Sci. Technol. 2, 109-123 (2012)

[28] E. Kreuzer, M. Steidl, Controlling Torsional Vibrations of Drill Strings Via Decomposition of Traveling Waves, Springer-Verlag, Berlin, 2011, pp. 515-531

[29] P.E. Troy Feese, Gudielines for preventing torsional vibration problems in reciprocating machinery, Gas Machinery Conference 2002, pp. 1-48

[30] Z.Q. Zhu, J.H. Leong, Aanalysis and mitigation of torsional vibration of PM brushless DC drives with direct torque controller, IEEE, 2011 pp. 1502-1509

[31] S. Seidlitz, R.J. Kuether, Comparison of noise floors of various torsional vibration sensors, The Society for Experimental Mechanics Springer, New York, 2012, pp. 153-168

Cite this article as: N. Xiao, X. Xu, R. Zhou, Study on torsional vibration of RT60 crane transmission system, Mechanics \& Industry 21, $210(2020)$ 